\title{
Electrogeneration of hydrogen peroxide applied to the peroxide-mediated oxidation of $(R)$-limonene in organic media
}

\author{
Camilo Enrique La Rotta Hernández* \\ Electrochemistry and Electroanalysis Laboratory \\ Department of Inorganic Chemistry \\ Institute of Chemistry \\ Federal University of Rio de Janeiro \\ CT, Bloco A Sala 634-A, Ilha do Fundão \\ CEP 21949-900, Rio de Janeiro, RJ, Brazil \\ Tel: 5502125627149 \\ E-mail: clarotta@iq.ufrj.br \\ Diogo Simon Werberich \\ Electrochemistry and Electroanalysis Laboratory \\ Department of Inorganic Chemistry \\ Institute of Chemistry \\ Federal University of Rio de Janeiro \\ CT, Bloco A Sala 634-A, Ilha do Fundão \\ CEP 21949-900, Rio de Janeiro, RJ, Brazil \\ Tel: 5502125627149 \\ E-mail: digosw@hotmail.com

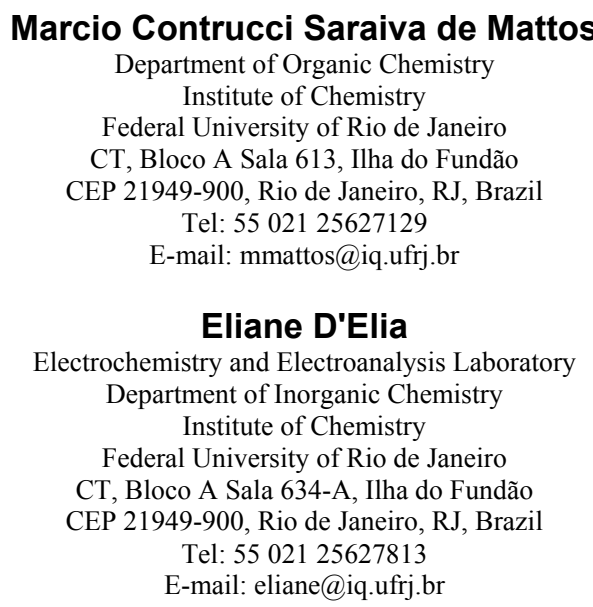

Financial support: We acknowledge the financial support of a FAPERJ research grant for Dr. C.E. La Rotta post-doctoral studies.

Keywords: Armoracia rusticana, bioelectrochemistry, carveol, carvone, horse-radish peroxidase, hydrogen peroxide electrogeneration, $(R)$-limonene.

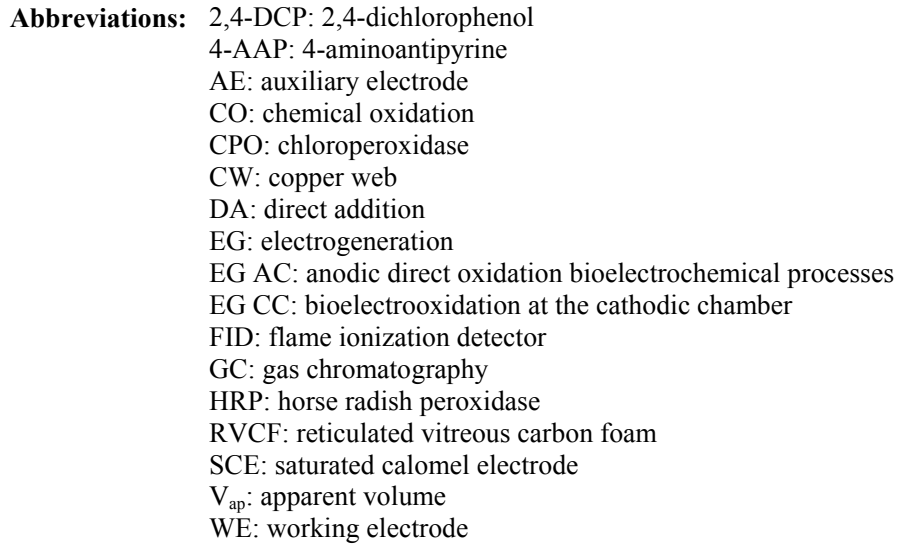

*Corresponding author 
Horse radish peroxidase (HRP) from Armoracia rusticana catalyses the oxidation of $(R)$-limonene into the oxidized derivatives carveol and carvone. This study compares the direct addition (DA) of hydrogen peroxide with its continuous electrogeneration (EG) during the enzymatic oxidation of $(R)$-limonene. Reaction mixtures containing HRP, $(R)$-limonene as substrate, and hydrogen peroxide, added directly or electrogenerated, in $100 \mathrm{mM}$ sodium-potassium phosphate buffer $\mathrm{pH}$ 7.0, at $25^{\circ} \mathrm{C}$ were studied. Two electrochemical systems for the hydrogen peroxide electrogeneration were evaluated, both containing as auxiliary electrode (AE) a platinum wire and saturated calomel electrode (SCE) as reference. Reticulated vitreous carbon foam (RVCF) and an electrolytic copper web (CW) were evaluated as working electrodes (WE). Results were compared in terms of hydrogen peroxide electrogeneration, $(R)$ limonene residual concentration or conversion and product selectivity. Best results in terms of maximum $\mathrm{H}_{2} \mathrm{O}_{2}$ concentration $(1.2 \mathrm{mM})$ were obtained using the $\mathrm{CW}$ electrode at $-620 \mathrm{mV}_{\text {SCE}}$, and continuous aeration. Use of the EG system under optimized conditions, which included the use of acetone $(30 \% \mathrm{v} / \mathrm{v})$ as a cosolvent in a 3 hrs enzymatic reaction, lead to a $45 \%$ conversion of $(R)$-limonene into carveol and carvone (2:1). In comparison to the results obtained with $D A$, the use of EG also improved the half-life of the enzyme.

The success of a new aroma or flavoring additive depends on a partnership between consumers and the industry to get an adequate product to the requirements of the market. The volume of additives grows daily in the Western European, American and Japanese markets and in the Latin American, Asian and Eastern European emerging markets. Among these, Brazil, China, India and Mexico are the most attractive. The flavor industry spends approximately 250 million dollar per year in research and development. The functional food area, which moved 10 billion dollar up-to 2005 , offers opportunities in this industry.

Essential oils from fruits are an abundant source of volatile terpenes, substances which are widely distributed in nature. The terpenes derived from essential oils are little functionalized and present chains of $\mathrm{C} 10$ (fraction of low boiling point) and $\mathrm{C} 15$ (fraction of high boiling). The orange juice industry, that moves around 2 billion dollar annually, has its market dominated by Brazil and the United States. The essential oil from orange is one of the main byproducts coming from orange juice processing, and is employed by the food, pharmaceutical, cosmetics and cleaning products industries.

(R)-limonene is the main constituent of orange and other citrus fruits skin oils (92 to 96\%), and is produced in amounts of up to 50,000 tons per year. Due to its low price, which may vary from US\$ 0.66 to 1.45 per $\mathrm{kg}$, this compound is an attractive starting point for the production of economically more interesting derivatives such as carvone, carveol and perillyl alcohol, used in fine chemistry (Lerner, 2003).

Although carvone can be obtained by extraction and purification from the essential oils of caraway, dill and spearmint seeds, it can also be produced by chemical and biotechnological synthesis. A few papers concerning the chemical synthesis of carvone were published after 1990 . Applications of carvone as fragrance and flavour, potato sprouting inhibitor, antimicrobial agent, building block and biochemical environmental indicator, along with its relevance in the medical field, justify the interest in this monoterpene.

Chemical oxidation (CO) of limonene in sodium citrateaqueous buffers, with and without low density polyethylene, was reported by Kutty et al. 1994. Limonene oxidation end-products included $(4 S)-(+)$-carvone, carveol, limonene oxide, perilaldehyde, linalool and the hydrolysis product, $\alpha$-terpineol (Figure 1). Wacker oxidation of limonene, using $\mathrm{PdCl}_{2} / \mathrm{CuCl}_{2} / \mathrm{O}_{2}$, carried out by Silva et al. (2002), also resulted in the formation of cis-carvyl acetate, trans-carvyl acetate, trans-carveol, carvone and $\alpha$-terpinyl acetate. Oxidation of limonene in $t$-butanol using $\mathrm{PdCl}_{2} / \mathrm{CuCl}_{2} / t$-butyl hydroperoxide was also done, and higher yields of oxidation products obtained in the presence of added chloride ions. On the other hand, during the $\mathrm{CO}$ of limonene with dioxygen in acetic acid solutions containing catalytic amounts of $\mathrm{Pd}(\mathrm{OAc})_{2}$, benzoquinone and $\mathrm{M}(\mathrm{OAc})_{2}(\mathrm{M}=\mathrm{Cu}$, Co or $\mathrm{Mn})$ reported by Gonçalves and Gusevskaya (2004) three isomeric allylic acetates, as such trans-2-acetoxy- $p$-mentha-1(7),8-diene, perilla acetate and trans-carveyl acetate were obtained. Limonene oxidation over $\mathrm{V}_{2} \mathrm{O}_{5} / \mathrm{TiO}_{2}$ catalysts yielded polymers, limonene oxide and limonene glycol as the main reaction products, as well as carveol and carvone obtained in small amounts (Oliveira et al. 2006).

Krings and Berger (1998) demonstrated the advantages of biotechnological flavors and fragrances, among which are: (i) the ability to label microbiologically produced compounds "natural product", making them attractive to increasingly health- and nutrition-conscious consumers; (ii) the potential of using industrially designed biochemical pathways for up-regulating metabolism; (iii) the possibility of producing chiral compounds responsible for odour perception; (iv) independence from agricultural and local conditions and (v) the usually straightforward product recovery. Furthermore, biocatalysis allows the production of enantiomericaly pure compounds, the modification of a molecule at chemically inert carbons and the selective modification of a specific functional group in multifunctional molecules. The disadvantages are related to common low water solubility, chemical instability, cytotoxicity and high volatility of terpenes. Some works have already been published describing successful production of carvone with whole cells or purified enzymes (Carvalho and Fonseca, 2006). 
Biotransformation of limonene to carvone were previously carried out using immobilized plant cells (Vanek et al. 1999) marine microalgae (Wise et al. 2002), fungi as Pleurotus ostratus (Onken and Berger, 1999), bacteria like Rhodococcus globerulus and Rhodococcus opacus (Duetz et al. 2001).

Although, the enzymatic oxidation of $(R)$-limonene has been successfully achieved using whole microbial cells and pure enzymes as mentioned above, the use of peroxidases has not been widely explored. On the other hand, the use of peroxidases in biocatalysis was also limited by the use of hydrogen peroxide as co-substrate, due to its inhibitory effect at high concentrations and slow reaction rates at lower concentrations (Nicell and Wright, 1997). One solution for this problem is the use of very low and controlled hydrogen peroxide supplementation, necessary just for the maintenance of an effective oxidation level, with no inhibitory effects. This can be achieved by the use of direct pulsed addition (DPA) or by in situ electrogeneration (EG). The electroenzymatic approach has provided a significantly lower and more easily controllable hydrogen peroxide formation rate than any other so far. EG has already been applied to some biocatalytical oxidations, such as, in the asymmetric oxidation of thioanisole by chloroperoxidase (CPO) (Lütz et al. 2004), the oxidation of chlorinated phenols (Kim and Moon, 2005; La Rotta et al. 2007), and the oxidation of dimethylaniline by horse radish peroxidase (HRP) (Chen and Nobe, 1993).

The purpose of this study is to verify the ability of horseradish peroxidase as biocatalyst during the oxidation of $(R)$ limonene for the production of carveol and carvone in reactions containing organic solvents. As we reported previously (La Rotta et al. 2007) the application of the hydrogen peroxide electrogeneration offers a very low and controlled hydrogen peroxide supplementation, necessary not just for the maintenance of an effective oxidation level but also for the prevention of undesirable inhibitory effects on the enzyme.

\section{MATERIALS AND METHODS}

\section{Biocatalyst features}

Two commercial preparations of horseradish peroxidase (EC. 1.11.1.10) from Armoracia rusticana were used in this study. The first was a salt-free preparation with $150 \mathrm{U} / \mathrm{mg}$ and Rz 1.4 purchased from Sigma-Aldrich Co. (St. Louis USA). The second one was a lyophilized preparation on diatomaceous earth and ammonium sulphate with 25 $\mathrm{KU} / \mathrm{mg}$ and $\mathrm{Rz} 1.2$, purchased from Toyobo Co. (Brazil), this preparation was dialyzed over-night against 10 $\mathrm{mmol} \cdot \mathrm{L}^{-1}$ potassium phosphate buffer $\mathrm{pH} 7.0$ prior to its use.

\section{Peroxidase activity determination}

For the determination of peroxidase activity, 2,4dichlorophenol $(2,4-\mathrm{DCP})$ was used as substrate which is oxidized by the enzyme in the presence of hydrogen peroxide and 4-aminoantipyrine (4-AAP) to produce colored products. Absorbance increase is proportional to the red derivative concentration, and it was followed at 510 $\mathrm{nm}\left(\varepsilon=7100 \mathrm{M}^{-1} \mathrm{~cm}^{-1}\right)$. One unit of peroxidase activity was defined as the amount ( $\mu$ moles) of red oxidized derivative formed per min at $\mathrm{pH} 7.0$ and $25^{\circ} \mathrm{C}$ (Metelitza et al. 1991).

\section{Enzymatic oxidation of $(R)$-limonene using direct addition (DA) of $\mathrm{H}_{2} \mathrm{O}_{2}$}

The effect of the molar ratio of $(R)$-limonene to hydrogen peroxide was evaluated using reaction mixtures containing 6.0 U.mL $\mathrm{mL}^{-1}$ of HRP; $0.5,1.0$ and $5.0 \mathrm{mmol} \cdot \mathrm{L}^{-1}$ of $(R)-$ limonene and $0.5,1.0$ and $5.0 \mathrm{mmol} \cdot \mathrm{L}^{-1} \mathrm{H}_{2} \mathrm{O}_{2}$ in 100 $\mathrm{mmol} \cdot \mathrm{L}^{-1}$ potassium phosphate buffer $\mathrm{pH} 7.0$ at $25^{\circ} \mathrm{C}$ and magnetic stirring at $200 \mathrm{rpm}$. All reactions were started by the addition of the hydrogen peroxide. As previous reports have shown (La Rotta et al. 2007) the use of a step-wise addition of hydrogen peroxide was advantageous. For this reason, the study was performed with the addition of 5 equal pulses to reach the desired final hydrogen peroxide concentration. This procedure was always performed during the first $\mathrm{hr}$ and all reactions were carried out for 4 hrs. In a similar way, the effect of the $\mathrm{CO}$, due to the hydrogen peroxide, was evaluated using the same reaction mixtures but without enzyme addition.

\section{Hydrogen peroxide electrogeneration}

The configurations for the electrochemical reactors used in this study were previously described during the bioelectrochemical oxidation of chlorinated phenols ( $\mathrm{La}$ Rotta et al. 2007) where both cells, single and bicompartmented were used. The electrochemical system was composed of a platinum wire as auxiliary electrode (AE) and asaturated calomel electrode (SCE) as reference. Reticulated vitreous carbon foam (RVCF) with $0.5 \mathrm{~cm}^{3}$ of apparent volume and an electrolytic copper web $(\mathrm{CW})$ of $27 \mathrm{~cm}^{2}$ apparent area were evaluated as working electrodes (WE). A cathodic potential of $-620 \mathrm{mV}_{\mathrm{SCE}}$ was applied, selected from previous studies (La Rotta et al. 2007). The hydrogen peroxide generation for both materials was followed for $3 \mathrm{hrs}$ using discontinuous pre-aeration during the first hr or continuous aeration during the whole reaction time. Aeration was made with pure $\mathrm{O}_{2}\left(5.0 \mathrm{~mL} \cdot \mathrm{min}^{-1}\right)$. Samples were taken during $4 \mathrm{hrs}$ from the reactors and the $\mathrm{H}_{2} \mathrm{O}_{2}$ was quantified using the methodology described previously by La Rotta et al. 2007.

\section{Electrochemical oxidation of $(R)$-limonene}

Preliminary experiments of $(R)$-limonene bioelectrochemical oxidation were performed using reaction mixtures containing $6.0 \mathrm{U} \cdot \mathrm{mL}^{-1}$ of $\mathrm{HRP} ; 1.0$ 
mmol $\cdot \mathrm{L}^{-1}$ of R-(+)-limonene and $\mathrm{H}_{2} \mathrm{O}_{2}$, electrogenerated at $620 \mathrm{mV}_{\mathrm{SCE}}$ and using both RVCF and CW electrodes with or without continuous aeration. These experiments were initially performed using an aqueous system of 100 $\mathrm{mmol} \cdot \mathrm{L}^{-1}$ potassium phosphate buffer $\mathrm{pH}$ 7.0. For further experiments cosolvents were used. All reactions were carried out during $4 \mathrm{hrs}$ at $25^{\circ} \mathrm{C}$ with magnetic stirring of $200 \mathrm{rpm}$. Reactions were started by the addition of HRP and the use of the electrolytic system at the specific potential. Control experiments were also carried out where the effect of the aeration, stirring, $\mathrm{CO}$ and anodic oxidation were determined using a bicompartmented cell.

\section{Effect of organic solvent on HRP activity}

To select the best organic cosolvent in terms of peroxidase activity retention and substrate solubility, four water miscible organic solvents were chosen and evaluated: dimethylformamide, isopropanol, acetronitrile and acetone. The cosolvents were added with increasing concentrations up to $60 \%(\mathrm{v} / \mathrm{v})$ in $100 \mathrm{mM}$ sodium-potassium phosphate buffer $\mathrm{pH}$ 7.0. Peroxidase activity was determined as described above.

\section{Extraction and quantification of residual $(R)$ - limonene and oxidized products}

Samples of $1.0 \mathrm{~mL}$ were taken from the reaction mixtures and were extracted twice with dichloromethane. Organic phases were pooled and dried using anhydrous sodium sulphate, stored at $-20^{\circ} \mathrm{C}$, and quantified by gas chromatography (GC) using a flame ionization detector (FID). A SE-54 capillary column $(25 \mathrm{~m} \times 0,2 \mathrm{~m}$ DI, 0,33 $\mathrm{mm}$ ) and hydrogen as carrier gas were used. The conditions during the chromatographic analysis were: flux rate 1.0 $\mathrm{mL} \cdot \mathrm{min}^{-1}\left(60^{\circ} \mathrm{C}, 30 \mathrm{kPa}\right)$; Injection temperature: $220^{\circ} \mathrm{C}$; Initial oven temperature: $60^{\circ} \mathrm{C}$; final oven temperature: $220^{\circ} \mathrm{C}$; heating ramp: $10^{\circ} \mathrm{C} \mathrm{min}^{-1}$. Detector temperature: $260^{\circ} \mathrm{C}$.

\section{Materials}

(R)-limonene, (S)-carveol (mixture of cis-and transisomers), $(S)$-carvone 2,4-DCP, 2,2'-azino-bis[3-ethylbenzothiazoline]-(6)-sulphonic acid diammonium salt (ABTS), 4-AAP were purchased from Sigma-Aldrich Co. (St. Louis - USA); Dibasic sodium phosphate, monobasic potassium phosphate, anhydrous sodium sulphate and hydrogen peroxide (30\% aqueous solution) were supplied by Merck Co. (Darmstadt - Germany). The latter was standardized by permanganometry. The RVCF (3\% density and 100 ppi) was supplied by Duocel - ERG Co. (Oakland USA) and the electrolytic CW $\left(27 \mathrm{~cm}^{2}\right)$ by Haver \& Boecker (Westfalen - Germany).

\section{Equipment}

A Shimadzu Multispec 1501 spectrophotometer (Shimadzu Co., Japan) with temperature-controlled cell was used for the enzymatic and colorimetric assays. The electrochemical measurements during the hydrogen peroxide electrogeneration and bioelectrooxidation of limonene were performed using a potentiostat/galvanostat Omnimetra PG 19 model (Brazil); and also a VoltaLab PGZ 301 Radiometer (Denmark) was used during the voltammetry studies. High resolution gas chromatography analysis were performed using a HP 5890-II chromatograph coupled to FID detector.

\section{RESULTS AND DISCUSSION}

\section{CO of $(R)$-limonene by DA of hydrogen peroxide}

To establish how the hydrogen peroxide oxidizes the $(R)$ limonene, experiments with DA of peroxide where performed in absence of enzyme. The results, which are summarized in Figure 2, demonstrate that $\mathrm{CO}$ increased proportional to the hydrogen peroxide concentration. According to this, with higher hydrogen peroxide concentrations the strongest oxidizing effect was observed when limonene to hydrogen peroxide ratios of $1: 1$ and $1: 2$ were employed, substrate oxidation between 4 to $6 \%$ was observed, with the predominance of carveol. At the higher ratios of 1:5 and 1:10 the strongest effects, ranging 12 to $18 \%$ of $\mathrm{CO}$, were observed, where carvone was the predominant derivative.

\section{Enzymatic oxidation of $(R)$-limonene employing $\mathrm{H}_{2} \mathrm{O}_{2}$ DA}

As can be seen in Table 1, HRP was able to oxidize $(R)$ limonene in the presence of $\mathrm{H}_{2} \mathrm{O}_{2}$ into carveol and carvone. For all concentration ratios evaluated, the increase in oxidation accompanies the increase of $\mathrm{H}_{2} \mathrm{O}_{2}$ concentration. Thus, $(R)$-limonene oxidation levels reached 65 and $69 \%$ when the stoichiometric limonene to hydrogen peroxide ratios of 1:2 and 1:5 were used. On the other hand, with a higher stoichiometric ration of 1:10, the oxidation level reached the highest levels of $70 \%$. Since no significant increase in oxidation was observed with the 1:10 ratio, compared with the lower ones, this could mark the limit for the enzymatic oxidation. This is clear for HRP mediated reactions since a $\mathrm{H}_{2} \mathrm{O}_{2}$ concentration higher than $5 \mathrm{mmol} \cdot \mathrm{L}^{-}$ ${ }^{1}$ might affect the enzyme, as shown by previous studies (Nicell and Wright, 1997; La Rotta et al. 2007). However, these oxidation levels combined the enzymatic oxidation and the substrate $\mathrm{CO}$ due to $\mathrm{H}_{2} \mathrm{O}_{2}$, as previously shown.

In general, the main oxidation products observed corresponded to carveol and carvone as shown in Figure 3. In the case of carveol, it was exclusively obtained with the low stoichiometric ratios of $1: 1$ and also with the use of a 5:1 ratio, which is deficient in $\mathrm{H}_{2} \mathrm{O}_{2}$, and contains substrate excess. For the higher stoichiometric ratios of 1:2 to 1:10, the formation of carvone was observed. Other products, such as perillyl alcohol and carvone oxide where also observed at trace concentrations. However, both did not derive from the enzymatic oxidation but from the $\mathrm{CO}$ of $(R)$-limonene. 


\section{The hydrogen peroxide electrogeneration}

According to Figure 4, the $\mathrm{H}_{2} \mathrm{O}_{2}$ production followed the same pattern when both the RVCF and CW electrodes were used. The increase in hydrogen peroxide concentration followed the increase of the cathodic overpotential up to $620 \mathrm{mV}_{\text {SCE }}$. At this potential, the highest hydrogen peroxide generation rates were observed during the first $30 \mathrm{~min}$, with accumulative maximum concentrations after $60 \mathrm{~min}$ of 1.2 and $0.35 \mathrm{mmol} \cdot \mathrm{L}^{-1}$ using continuous aeration or 0.77 and $0.25 \mathrm{mmol} \cdot \mathrm{L}^{-1}$ for discontinuous aeration when $\mathrm{CW}$ and RVCF electrodes were used, respectively. Although, continuous aeration might be considered a better choice than the use of pre-aeration, the choice of the latter will be justified, in part, by the reduced evaporation of the volatile substrate.

As the literature showed recently, copper, gold and carbonaceous materials such as graphite felts or RVCF have a good efficiency for hydrogen peroxide electrogeneration (Lütz et al. 2004). On the other hand, as this study will show as follows, an advantageous hydrogen peroxide stabilization will not justify the detrimental effect of a severe increase in substrate adsorption (up to 40\%) when graphite-like or reticulated carbon materials will be used.

\section{Bioelectrochemical oxidation of $(R)$-limonene in a single-chamber reactor}

Initial experiments containing $0.5 \mathrm{mmol} \cdot \mathrm{L}^{-1}$ of $(R)$ limonene in an aqueous medium demonstrated that magnetic stirring at $200 \mathrm{rpm}$ and continuous aeration caused the complete loss of substrate. Furthermore, no oxidized products were observed from the electrochemical, chemical or from the enzymatic oxidations. One way to avoid this substrate loss during the bioelectrochemical process is to start performing the aeration one $\mathrm{hr}$ prior to the addition of the substrate, even when lower levels of peroxide generation might be expected. During the experiments that followed, a $(R)$-limonene loss of only $10 \%$ was observed, due to the aeration and stirring processes, and of $25 \%$ and $5 \%$ due to the adsorption on the electrode surfaces when the RVCF and CW electrodes were used, respectively. The substrate adsorptionwas estimated using the waste from the electrode cleaning with dichloromethane. This waste was quantified by GC. These control experiments were also performed for higher substrate concentrations $\left(1.0\right.$ and $\left.5.0 \mathrm{mmol} \cdot \mathrm{L}^{-1}\right)$ resulting in proportional values for each concentration. In all cases, no anodic oxidation could be determined since the experiments were performed in a single chamber cell.

Figure 5 shows the effect of the aeration mode on the bioelectrochemical oxidation of a $(R)$-limonene (1.0 $\left.\mathrm{mmol} \cdot \mathrm{L}^{-1}\right)$ in two different media: aqueous dispersion and a system containing $20 \%(\mathrm{v} / \mathrm{v})$ of acetonitrile as cosolvent. These electrolysis were performed using a RVCF electrode $\left(\mathrm{V}_{\text {ap }}=0,5 \mathrm{~cm}^{3}\right)$ at $-620 \mathrm{mV}_{\mathrm{ECS}}$. As it can be seen, best results in terms of $(R)$-limonene conversion of $41 \%$ were obtained when the electrochemical generation of $\mathrm{H}_{2} \mathrm{O}_{2}$ was performed using continuous aeration plus stirring and using acetonitrile $20 \%$ as cosolvent, followed by $32 \%$ of substrate oxidation when an aqueous dispersion was used. As shown in Figure 6, control experiments demonstrated no significant differences in terms of substrate loss values between the two aeration modes studied. However, slightly more limonene was lost due to $\mathrm{CO}$ and air stripping when continuous aeration was used. This was evidently related to the highest $\mathrm{H}_{2} \mathrm{O}_{2}$ concentration obtained with a continuous oxygen supplementation and with the air-drag effect cause by the oxygen stream.

On the other hand, experiments performed using the $\mathrm{CW}$ electrode $\left(\mathrm{A}_{\mathrm{ap}}=27 \mathrm{~cm}^{2}\right)$, produced 65 and $71 \%$ of $(R)$ limonene conversion when discontinuous and continuous aerations were used in acetonitrile $20 \%$, respectively (data not shown). These higher values can be explained by the fact of a larger electrode surface area which is closely related with the peroxide concentration as was previous described by Kim and Moon, (2005) and La Rotta et al. (2007). However, the continuous aeration promoted a substrate loss of up to $25 \%$. In addition, a higher CO of $8 \%$ due to the hydrogen peroxide was also observed for the $\mathrm{CW}$ electrode. Even so, when acetronitrile $20 \%$ was used as cosolvent, the substrate loss due to the electrode adsorption fell from approximately $28 \%$ to $15 \%$.

\section{Bioelectrochemical oxidation in bicompartmented cells}

When the bioelectrochemical oxidation of $(R)$-limonene was performed using a bicompartmented cell, it was possible to estimate the substrate anodic oxidation due to the electrochemical process itself. This anodic oxidation reached $7 \%$ when either of the electrodes was used. As shown in Figure 7, similar levels of $(R)$-limonene oxidation (around 22\%) were obtained using discontinuous as well as continuous aeration and the RVCF electrode. In contrast, when the $\mathrm{CW}$ electrode was used, higher levels of enzymatic $28 \%$ and $34 \%$ of limonene conversion were obtained using discontinuous and continuous aeration, respectively.

As shown in Figure 8, control experiments using discontinuous aeration, demonstrated once more that when employing the RVCF electrode, the highest substrate sorption (13.2\%) was achieved. For the CW electrode a CO of $9.6 \%$ (approximately 2 times higher than the RVCF electrode) was observed. These levels were evidently related to the higher concentration of hydrogen peroxide achieved as previously discussed. For both electrodes an anodic oxidation around $7 \%$ was observed.

It should be noted that even when HRP drives the oxidation of $(R)$-limonene to high reaction rates, there is an important component from the direct oxidation, which is due to the electrochemical process itself. In the end this will also contribute to the whole bioelectrochemical conversion. As 
such the bioelectrochemical process resulted in the production of mainly $(S)$-carveol, with traces of $(S)$-carvone when a RVCF electrode was used. And for CW electrodes due the highest peroxide generation both carveol and carvone were produce. However, as showed in Table 2, the carveol: carvone ratios depended on the aeration mode employed. Thus, with discontinuous aeration a 1:1 ratio was obtained while continuous aeration resulted in a $3: 1$ ratio. In contrast, the quantifications made from the anodic chamber also showed the production of low concentrations of carveol and trace concentrations of limonene oxide and carvone oxide.

\section{Effect of solvent system over HRP activity}

Four water miscible cosolvents were evaluated in order to obtain a more homogeneous system, that gave a clear reaction medium for subsequent UV-Vis spectrophotometric analysis. This evaluation also led to higher activity of the enzyme and therefore higher conversion levels due to the increase in the substrate solubility and availability to the enzyme. The effect of the solvents on enzyme activity (measured as peroxidase activity) is shown in Figure 9. In all cases, activity loss incresed in response to increase in organic solvent concentration. Consequently, the most remarkable negative effect on HRP activity was obtained using isopropanol, which caused the loss of $50 \%$ of the initial activity, even at low concentrations. Similar results were observed for acetonitrile. Best results were obtained using dimethylformamide and especially acetone. The latter, led us to obtain high peroxidase activity levels (up to $80 \%$ residual activity) with a solvent concentration of $40 \%$.

It is evident from Figure 9 that acetone concentration up to $40 \%(\mathrm{v} / \mathrm{v})$ can be used. However, we decided to use $30 \%$ for further experiments, since it yielded the same results in terms of an homogeneous and clear solution of $(R)$ limonene, and also HRP activity retention. Improvements in terms of enzyme activity and substrate conversion were evident, as shown in Figure 10. When both electrodes, RVCF and CW, were tested using acetone (30\%) as cosolvent, the final conversion was 1-fold time higher than when acetonitrile $20 \%$ was used. Consequently, maximum conversion levels of $45 \%$ and $40.5 \%$ were reached using the $\mathrm{CW}$ and RVCF electrodes, respectively, with continuous aeration. Good conversion levels of $40.3 \%$ were also obtained when the $\mathrm{CW}$ electrode was used with discontinuous aeration. Substrate loss due to adsorption on the electrode surfaces was lower when acetone was used instead of acetonitrile. Nevertheless, similar results were observed for the anodic oxidation, $\mathrm{CO}$ and loss by stirring. In these cases, the composition of the binary system did not affect the electrochemical process, and therefore the same concentrations of hydrogen peroxide were obtained using the already mentioned electrochemical conditions.

\section{CONCLUDING REMARKS}

This study evaluated the effectiveness of horse-radish peroxidase as biocatalyst during the oxidation of $R-(+)$ limonene for the production of carveol and carvone. The bioelectrochemical processes for the hydrogen peroxide electrogeneration and the enzymatic oxidation of $R-(+)-$ limonene was studied in aqueous medium and water miscible organic systems. The electrogeneration of hydrogen peroxide was possible in both systems using reticulated vitreous carbon electrodes as well as copper electrodes. Although, the RVCF electrode had already been reported as the best electrode in terms of generation and stabilization of the hydrogen peroxide, some of its intrinsic features such as high porosity made it inappropriate for use with highly absorbable or volatile substances such as terpenes. Best results in terms of $R$-(+)-limonene conversion were achieved when an organic medium containing $30 \%$ acetone and continuous aeration were used. However, no changes in product distribution were observed between the organic systems and the aqueous medium evaluated. Some caution must be taken, since this aeration mode also promotes a high loss of substrate by airdragging. Low chemical and anodic oxidation levels of less than $10 \%$ were observed in all cases. The efficiency of the DA of peroxide in terms of enzymatic oxidation was similar or better than the electrochemical approach, even though the latter presented lower inactivation rates, and longer half-life and work-life times as show in previous research studies (La Rotta et al. 2007).

Depending on the electrode material, aeration mode and the available concentration of hydrogen peroxide, the product distribution can be different. As such, in deficient concentration of peroxide the predominant product was $(S)$ carveol. On the other hand, with a peroxide concentration increase, the production of $(S)$-carveol and $(S)$-carvone can be observed in ratios of $1: 1$ and 3:1 using hydrogen peroxide electrogeneration.

In future studies, we intend to implement the use of chemical mediators that will improve the oxidation yields. On the other hand, we are also interested in the enatio- and regioselectivities in the oxidation of other terpenes catalyzed using HRP and other peroxidases such as CPO.

\section{ACKNOWLEDGMENTS}

We are especially grateful to Prof. Elba P.S. Bon (Enzyme Technology Laboratory IQ/UFRJ) and to Prof. Carlos Riehl (Dept. of Analytical Chemistry, IQ/UFRJ) for the analytical facilities.

\section{REFERENCES}

CARVALHO, Carla C.C.R. de and FONSECA, M. Manuela R. da. Carvone: Why and how should one bother to produce this terpene. Food Chemistry, April 2006, vol. 95 , no. 3, p. 413-422. 
CHEN, J.K. and NOBE, K. Oxidation of dimethylaniline by horseradish peroxidase and electrogenerated peroxide. I. Free enzyme studies. Journal of the Electrochemical Society, February 1993, vol. 140, no. 2, p. 299-308.

DUETZ, Wouter A.; FJALLMAN, Ann H.M.; REN, Shuyu Y.; JOURDAT, Catherine and WITHOLT, Bernard. Biotransformation of D-limonene to $(+)$ trans-carveol by toluene-grown Rhodococcus opacus PWD4 cells. Applied and Environmental Microbiology, June 2001, vol. 67, no. 6, p. $2829-2832$.

GONÇALVES, José Ailton and GUSEVSKAYA, Elena V. Palladium catalyzed oxidation of monoterpenes: multistep electron transfer catalytic systems $\mathrm{Pd}(\mathrm{OAc})_{2} /$ benzoquinone/ $\mathrm{M}(\mathrm{OAc})_{2}(\mathrm{M}=\mathrm{Cu}, \mathrm{Co}$ or $\mathrm{Mn})$ for the allylic oxidation of limonene with dioxygen. Applied Catalysis A: General, February 2004, vol. 258, no. 1, p. 9398.

KRINGS, U. and BERGER, R.G. Biotechnological production of flavors and fragrances. Applied Microbiology and Biotechnology, January 1998, vol. 49, no. 1, p. 1-8.

KIM, G.-Y. and MOON, S.-H. Degradation of pentachlorophenol by an electroenzymatic method using immobilized peroxidase enzyme. Korean Journal of Chemical Engineering, January 2005, vol. 22, no. 1, p. 5260.

KUTTY, V.; BRADDOCK, R.J. and SADLER, G.D. Oxidation of D-limonene in presence of low-density polyethylene. Journal of Food Science, March 1994, vol. 59 , no. 2, p. 402-405.

LA ROTTA H., Camilo E.; D'ELIA, Eliane and BON, Elba P.S. Chloroperoxidase mediated oxidation of chlorinated phenols using electrogenerated hydrogen peroxide. Electronic Journal of Biotechnology [online]. 15 January 2007, vol. 10, no. 1 [cited date]. Available from Internet: http://www.ejbiotechnology.info/content/vol10/issue1/full/ 5/index.html. ISSN 0717-3458.

LERNER, Ivan. D-Limonene impacted by events in Brazil and Asia. (Specialties). Chemical Market Reporter, June 2003, vol. 263, no. 25, p. 16.

LÜTZ, Stephan; STECKHAN, Eberhard and LIESE, Andreas. First asymmetric electroenzymatic oxidation catalyzed by a peroxidase. Electrochemistry Communications, June 2004, vol. 6, no. 6, p. 583-587.

METELITZA, Dmitriy I.; LITVINCHUK, Alexandra V. and SAVENKOVA, Marina L. Peroxidase-catalysed cooxidation of halogen-substituted phenols and 4aminoantipyrine. Journal of Molecular Catalysis, August 1991, vol. 67, no. 3, p. 401-411.

NICELL, James A. and WRIGHT, Harold. A model of peroxidase activity with inhibition by hydrogen peroxide.
Enzyme and Microbial Technology, September 1997, vol. 21, no. 4, p. 302-310.

OLIVEIRA, P.; ROJAS-CERVANTES, M.L.; RAMOS, A.M.; FONSECA, I.M.; REGO, A.M.B. and VITAL, J. Limonene oxidation over $\mathrm{V}_{2} \mathrm{O}_{5} / \mathrm{TiO}_{2}$ catalysts. Catalysis Today, December 2006, vol. 118, no. 3-4, p. 307-314.

ONKEN, J. and BERGER, R.G. Effects of $R$-(+)-limonene on submerged cultures of the terpene transforming basidiomycete Pleurotus sapidus. Journal of Biotechnology, April 1999, vol. 69, no. 2-3, p. 163-168.

SILVA, A.D.; PATITUCCI, M.L.; BIZZO, H.R.; D'ELIA, E. and ANTUNES, O.A.C. Wacker $\mathrm{PdCl}_{2}-\mathrm{CuCl}_{2}$ catalytic oxidation process: oxidation of limonene. Catalysis Communications, September 2002, vol. 3, no. 9, p. 435440.

VANEK, Tomás; VALTEROVA, Irena; VANKOVA, Radomira and VAISAR, Tomás. Biotransformation of (-)limonene using Solanum aviculare and Dioscorea deltoidea immobilized plant cells. Biotechnology Letters, July 1999, vol. 21 , no. 7, p. 625-628.

WISE, Mitchell L.; RORRER, Gregory L.; POLZIN, Jason $\mathrm{J}$. and CROTEAU, Rodney. Biosynthesis ofmarine natural products: Isolation and characterization of a myrcene synthase from cultured tissues of the marine red alga Ochtodes secundiramea. Archives of Biochemistry and Biophysics, April 2002, vol. 400, no. 1, p. 125-132. 


\section{APPENDIX}

\section{FIGURES}<smiles>C=C(C)[C@@H]1CC=C(C)[C@H](O)C1</smiles>

(S)-Carveol, mixture of isomers<smiles>C=C(C)[C@H]1CC=C(CO)CC1</smiles>

(S)-Perillyl alcohol<smiles>C=C(C)[C@H]1CC=C(C)C(=O)C1</smiles>

(R)-Carvone<smiles>C=C(C)[C]1CC=C(C)C(=O)C1</smiles>

(S)-Carvone<smiles>C=C(C)C1CCC2(C)OC2C1</smiles>

(R)-Limonene Oxide,
mixture of cis and trans isomers<smiles>CC1=CCC(C(C)(C)O)CC1</smiles>

(S)-a-Terpineol

Figure 1. Chemical structures for $(R)$ - and $(S)$-Limonene and their main oxidized derivatives with industrial interest.

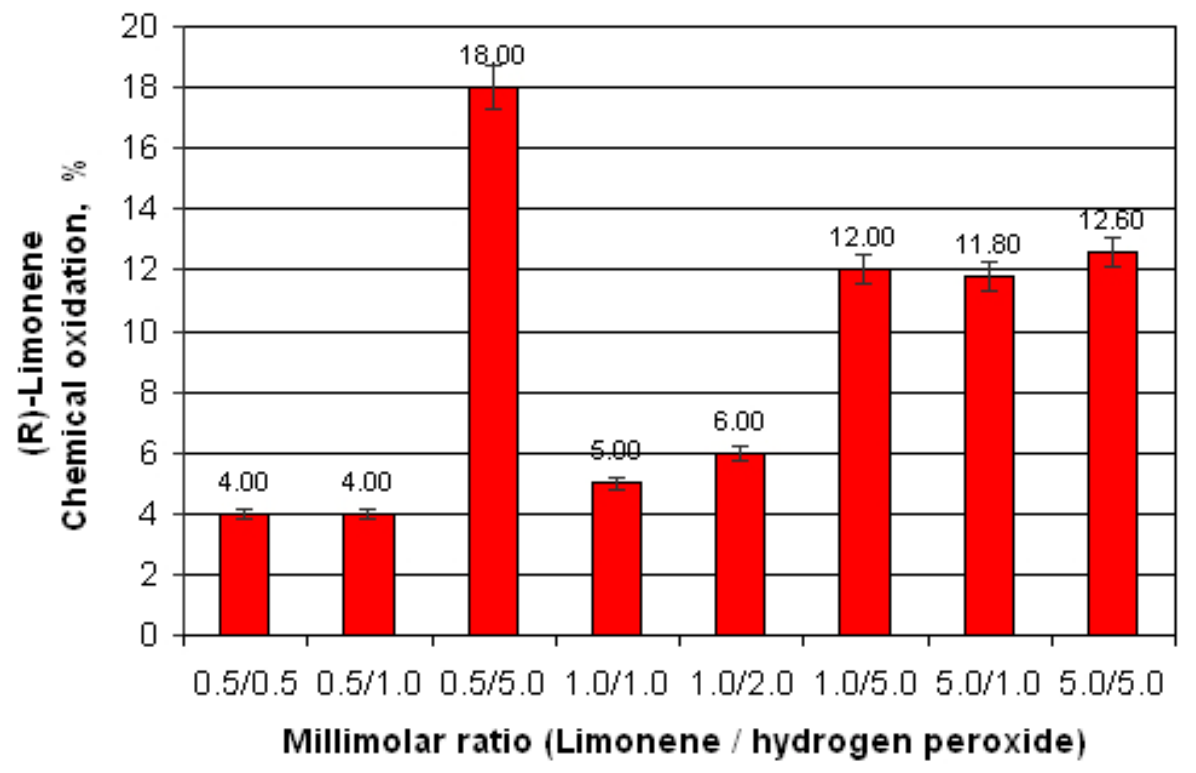

Figure 2. Control reactions for $\mathrm{CO}$ of $(R)$-limonene $(1.0 \mathrm{mM})$ with direct additon of hydrogen peroxide. 


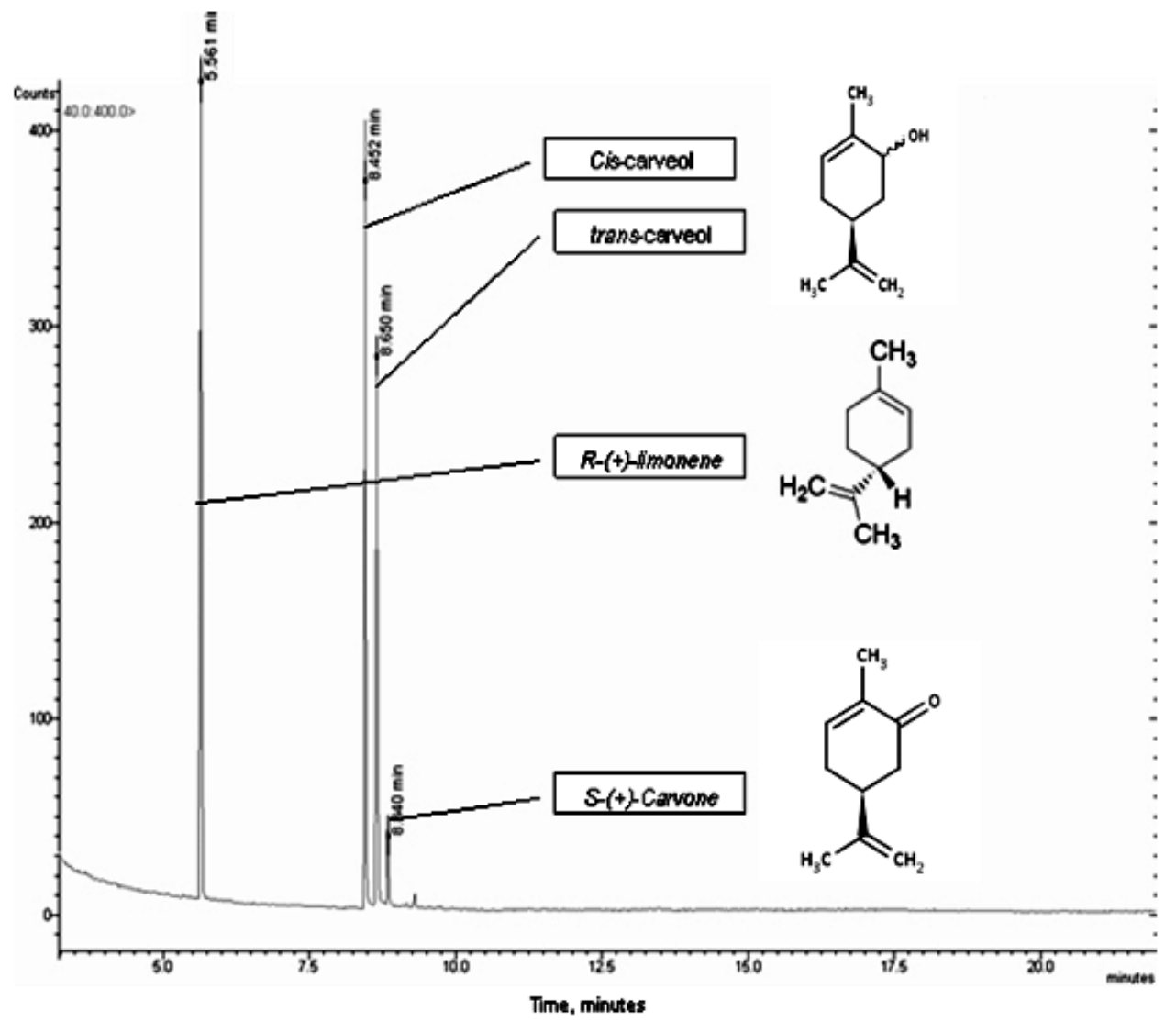

Figure 3. Typical CG chromatogram obtained during the analysis of the enzymatic oxidation of $(R)$-limonene and derivatives. 
La Rotta, C.E. et al.

a

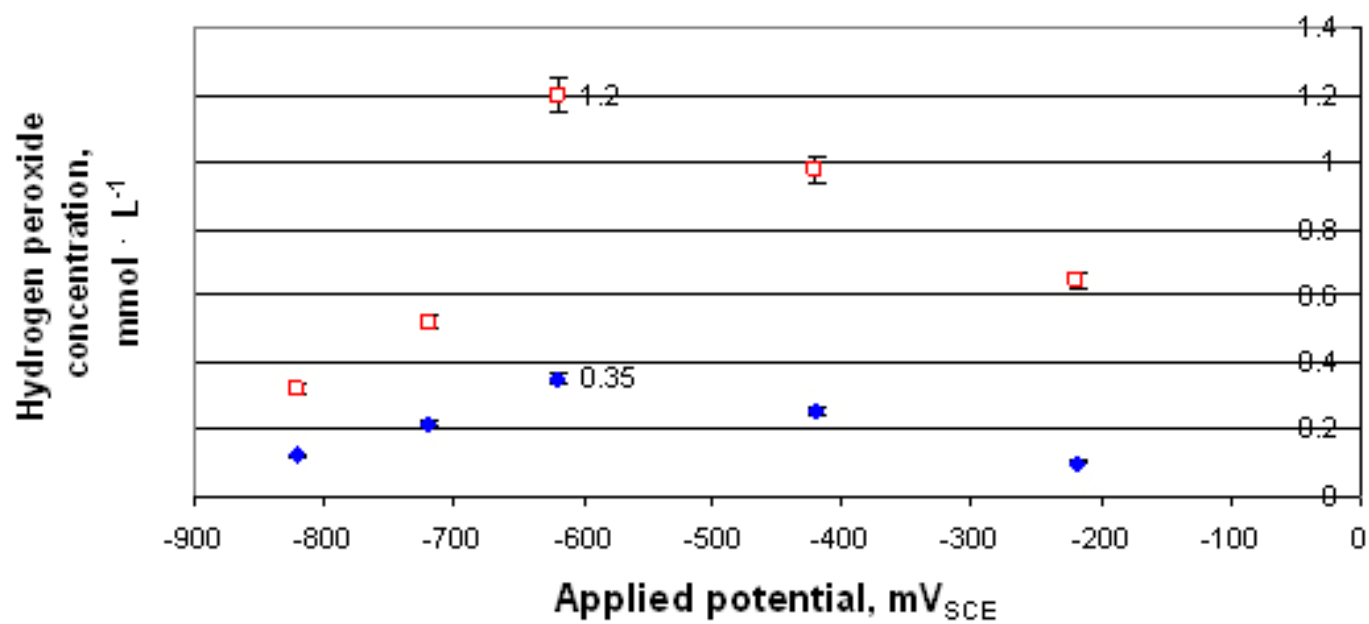

口 CW - RVCE

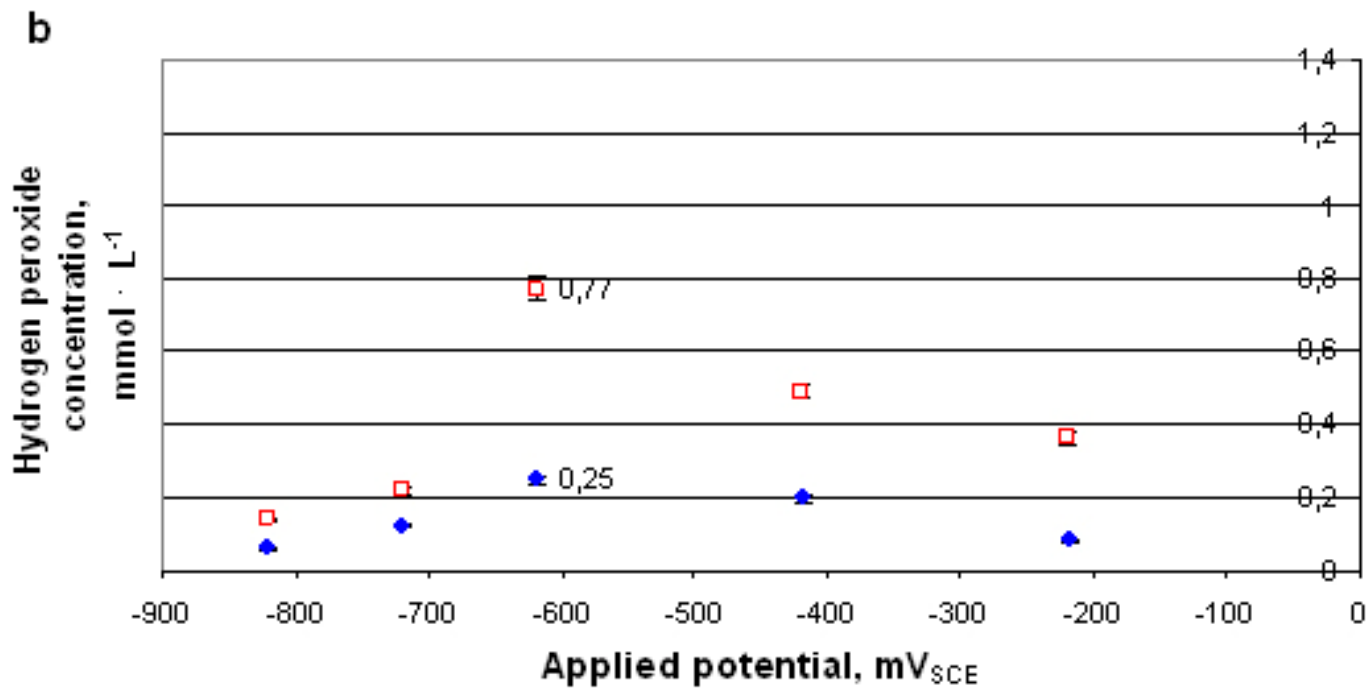

口 CW • RVCE

Figure 4. Effect of the work electrode material (RVCF and CW) and the applied potential over the electrochemical generation of hydrogen peroxide. Using:

(a) Continuous aeration.

(b) Discontinuous aeration. 


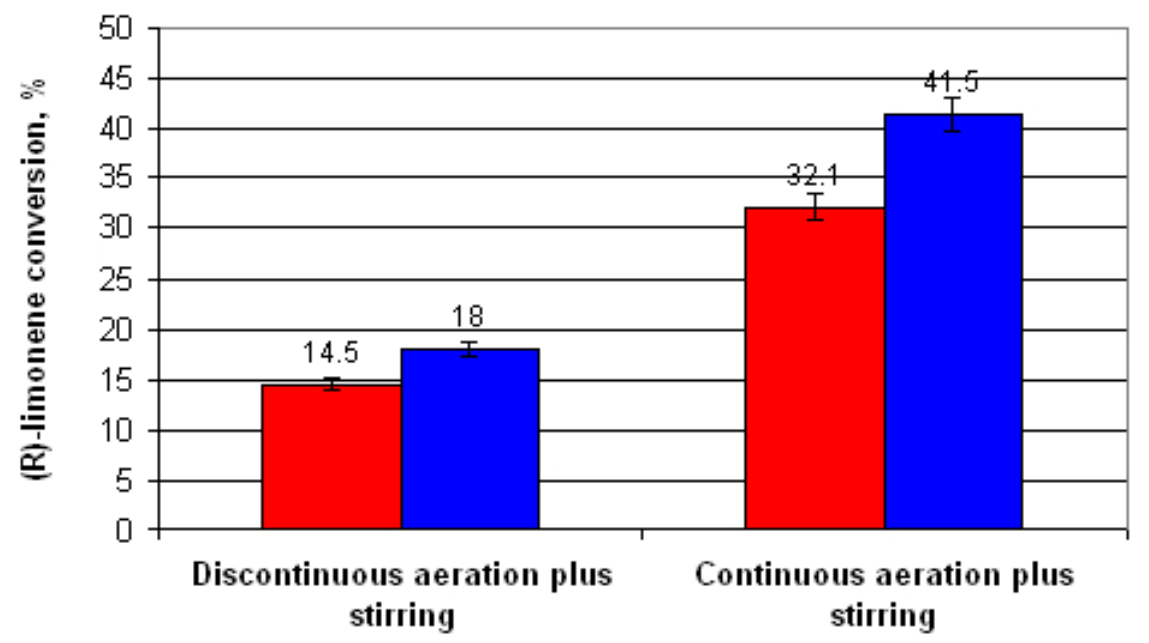

Figure 5. Effect of the aeration mode during preliminar experiments of bioelectrochemical oxidation of $(R)$-limonene $(1.0$ $\mathrm{mmol} \cdot \mathrm{L}^{-1}$ ) using RVCF electrode: Aqueous dispersion in potassium phosphate buffer $\mathrm{pH} 7.0$ (red bars) and with acetonitrile $20 \%$ v/v (blue bars) as cosolvent.
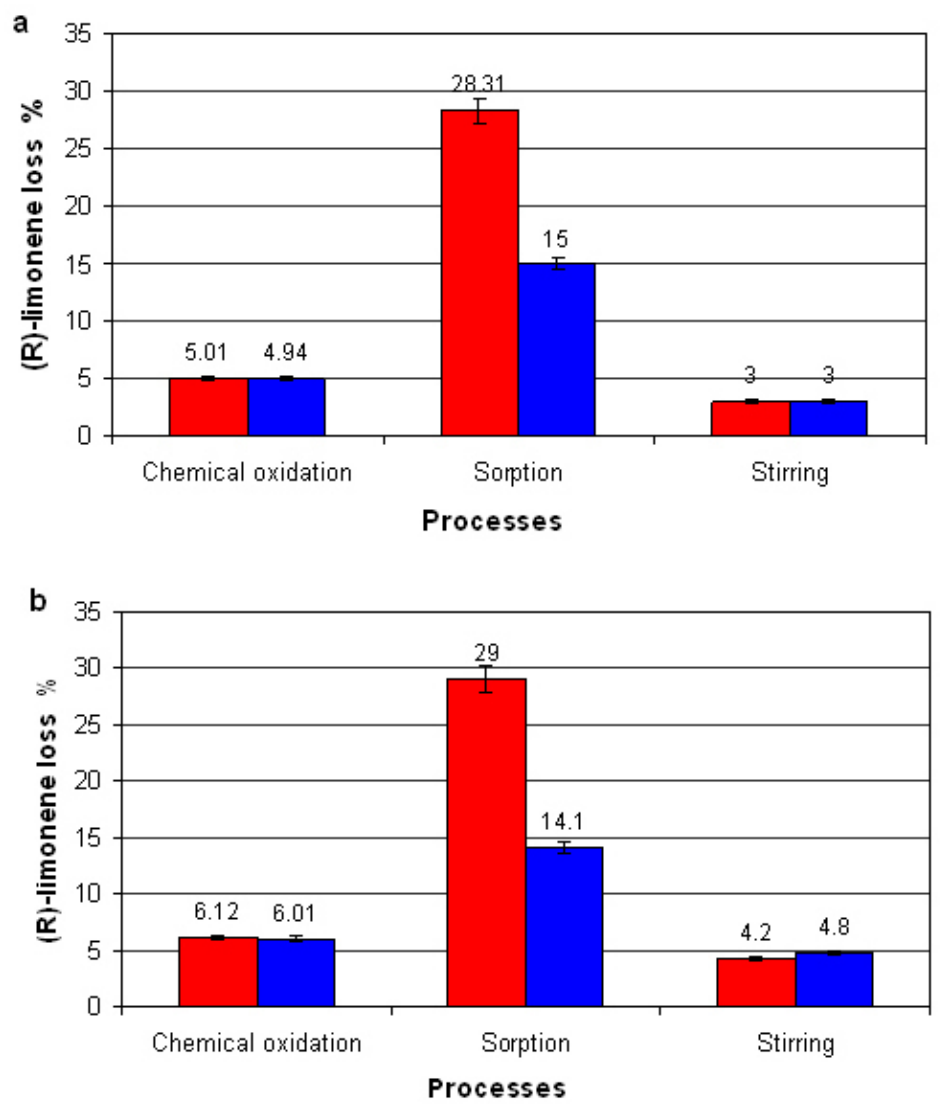

Figure 6. Loss of substrate due to the operations involved in the preliminar experiments of bioelectrochemical oxidation of $(R)$ limonene $\left(1.0 \mathrm{mmol} \cdot \mathrm{L}^{-1}\right)$ using RVCF electrode in aqueous dispersion in potassium phosphate buffer $\mathrm{pH} 7.0$ (red bars) and with acetonitrile $20 \%$ (blue bars) as cosolvent.

(a) Discontinuous aeration.

(b) Continuous aeration. 


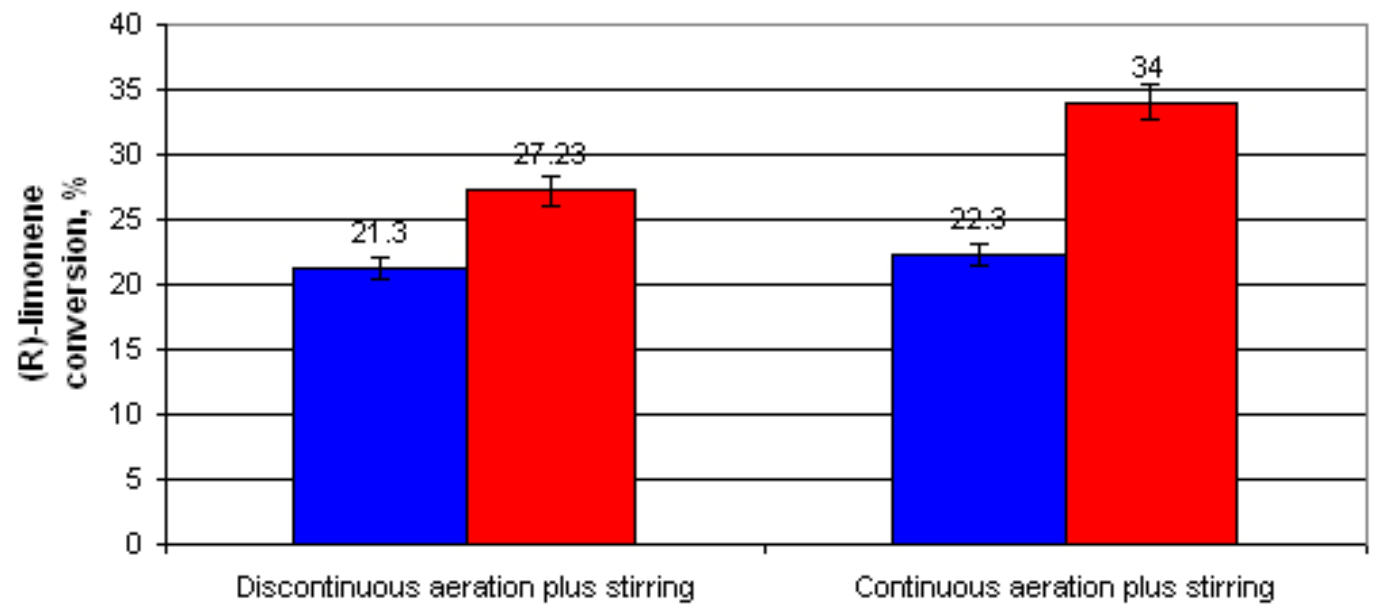

Aeration mode

RVCF $\square$ CW

Figure 7. Effect of aeration mode and work electrode material RVCF (white bars) and CW (grey bars) on the bioelectrochemical oxidation of $(R)$-limonene $\left(1.0 \mathrm{mmol} \cdot \mathrm{L}^{-1}\right)$ in a bicompartmented cell reactor.

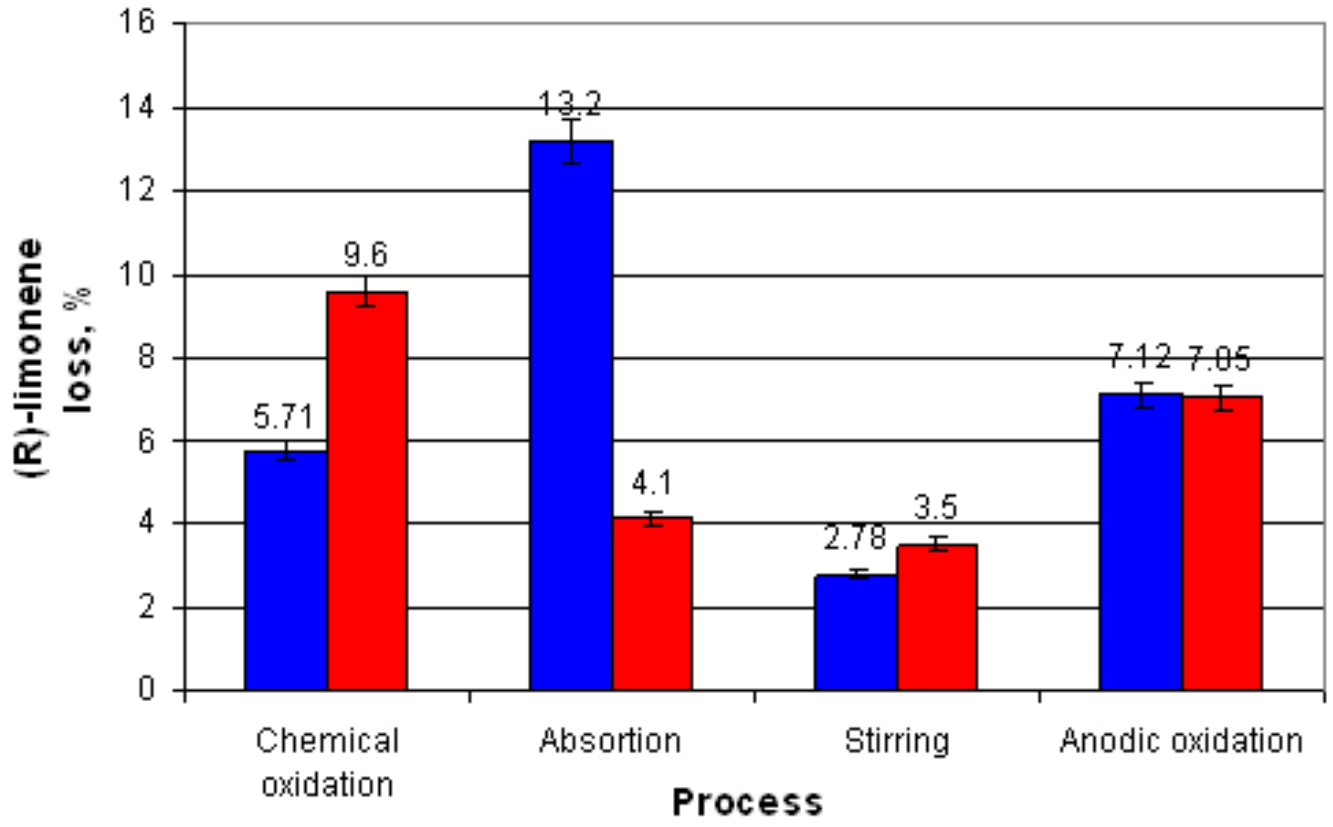

RVCF aCW

Figure 8. Substrate loss due to the operations involved in experiments of bioelectrochemical oxidation using discontinous aereation. Acetonitrile $20 \%$ as cosolvent in $100 \mathrm{mmol} \cdot \mathrm{L}^{-1}$ sodium-potassium phosphate buffer $\mathrm{pH} 7.0$, using the bicompartmented cell reactor. 
Electrogeneration of hydrogen peroxide applied to the peroxide-mediated oxidation of $(R)$-limonene in organic media

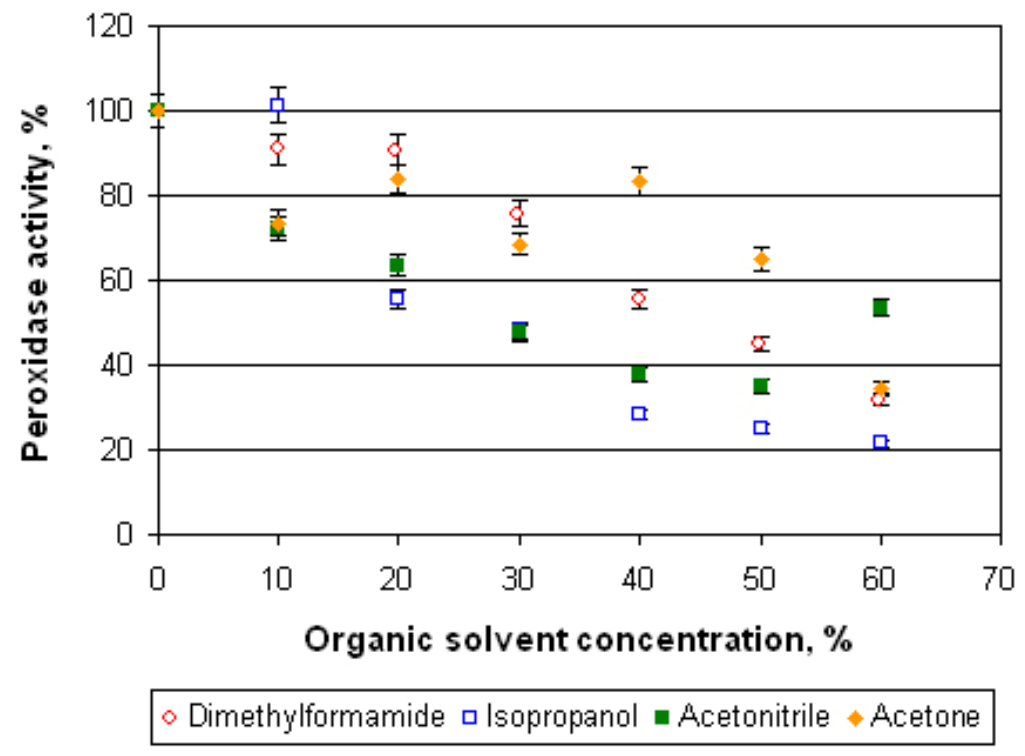

Figure 9. Effect of type and concentration of organic solvent on the peroxidase activity of horseradish peroxidase.

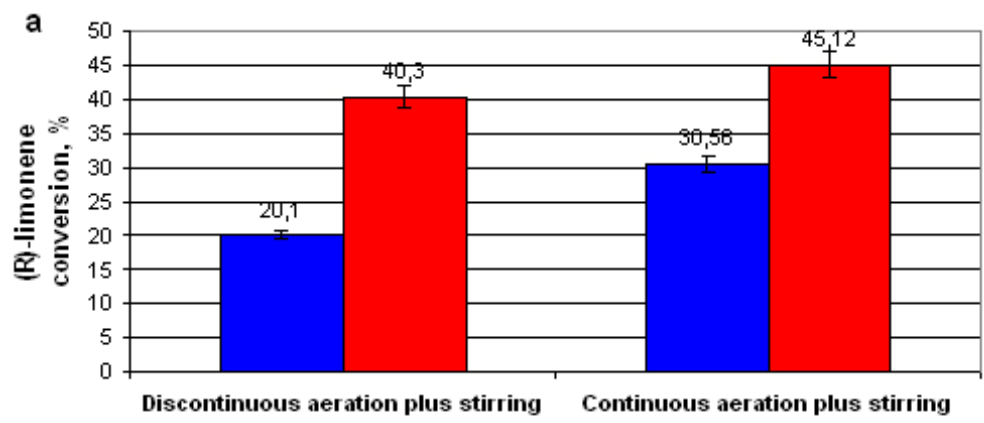

$\square$ RVOF $\square$ CW

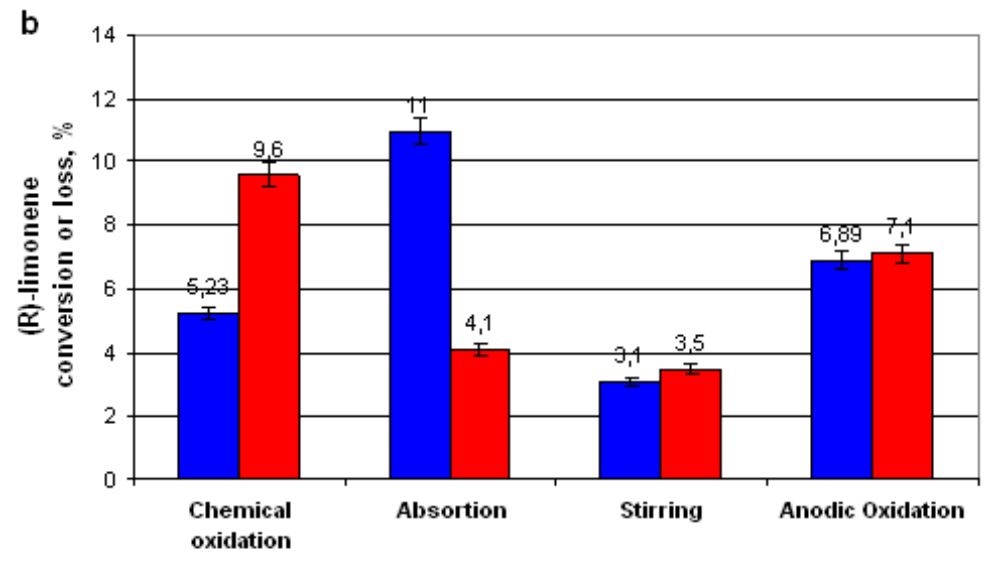

aVCF aCW

Figure 10. Effect of the aeration mode and type of electrode RVCF (blue bars) and CW (red bars) on the bioelectrochemical oxidation of $(R)$-limonene $\left(1.0 \mathrm{mmol} \cdot \mathrm{L}^{-1}\right)$ with acetone $30 \%(\mathrm{v} / \mathrm{v})$ as cosolvent in $100 \mathrm{mmol} \cdot \mathrm{L}^{-1}$ sodium-potassium phosphate buffer $\mathrm{pH} 7.0$, using the bicompartmented cell reactor.

(a) Effect of aereation mode.

(b) Substrate loss due to the operations involved in experiments of bioelectrochemical using discontinous aereation. 


\section{TABLES}

Table 1. Enzymatic oxidation of $(R)$-limonene $\left(1.0 \mathrm{mmol} \cdot \mathrm{L}^{-1}\right)$ using HRP with direct additon of hydrogen peroxide.

\begin{tabular}{|c|c|c|c|c|c|}
\hline $\begin{array}{c}(R) \text {-limonene } \\
\text { initial } \\
\text { concentration }\end{array}$ & $\mathrm{H}_{2} \mathrm{O}_{2}$ & $\begin{array}{l}\text { Stoichiometric } \\
\text { ratio } \\
\text { Limonene/ } \mathrm{H}_{2} \mathrm{O}_{2}\end{array}$ & $\begin{array}{l}(R) \text {-limonene } \\
\text { residual } \\
\text { concentration }\end{array}$ & Conversion & $\begin{array}{l}\text { Observed } \\
\text { products/Proportion }\end{array}$ \\
\hline $\mathrm{mmol} \cdot \mathrm{L}^{-1}$ & $\mathrm{mmol} \cdot \mathrm{L}^{-1}$ & $\mathrm{mmol} \cdot \mathrm{L}^{-1}$ & $\mathrm{mmol} \cdot \mathrm{L}^{-1}$ & $\%$ & \\
\hline 0.5 & 1 & $1: 2$ & 0.36 & 28.00 & $(S)$-Carveol + (S)-Carvone (1:1) \\
\hline 1 & 1 & $1: 1$ & 0.61 & 38.75 & $(S)$-Carveol \\
\hline 0.5 & 0.5 & $1: 1$ & 0.45 & 10.00 & $(S)$-Carveol \\
\hline 5 & 1 & $5: 1$ & 4.22 & 15.60 & (S)-Carveol \\
\hline 1 & 2 & $1: 2$ & 0.35 & 65.00 & $(S)$-Carveol + (S)-Carvone (3:1) \\
\hline 5 & 5 & $1: 1$ & 2.32 & 53.60 & $(S)$-Carveol + (S)-Carvone (2:1) \\
\hline 1 & 5 & $1: 5$ & 0.31 & 69.00 & $(S)$-Carveol + (S)-Carvone (1:3) \\
\hline 0.5 & 5 & $1: 10$ & 0.15 & 70.00 & $(S)$-Carveol + $(S)$-Carvone (1:4) \\
\hline
\end{tabular}


Table 2. Product distribution according to oxidation type: Electroenzymatic (EG CC), CO and electro oxidation (EG AC).

\begin{tabular}{|c|c|c|c|c|c|c|}
\hline \multirow[t]{2}{*}{$\begin{array}{l}\text { Oxidation } \\
\text { type }\end{array}$} & \multicolumn{4}{|c|}{$\begin{array}{c}\mathrm{H}_{2} \mathrm{O}_{2} \\
\text { Electrogeneration }\end{array}$} & \multirow{2}{*}{$\begin{array}{c}\text { Approximated } \\
\text { stoichiometric } \\
\text { ratio } \\
\text { Limonene/ } \mathrm{H}_{2} \mathrm{O}_{2} \\
\mathrm{mmol} \cdot \mathrm{L}^{-1}\end{array}$} & \multirow[t]{2}{*}{ Observed products/proportion } \\
\hline & Aeration mode & Electrode used & $\mathrm{mV}_{\mathrm{SCE}}$ & $\mathrm{mmol} \cdot \mathrm{L}^{-1}$ & & \\
\hline EG AC & Continuous & $\mathrm{CW}$ & -620 & - & - & $(S)$-Carveol \\
\hline EG CC & Continuous & $\mathrm{CW}$ & -620 & 1.2 & $1: 1.2$ & $(S)$-Carveol + (S)-Carvone (3:1) \\
\hline $\mathrm{CO}$ & Continuous & $\mathrm{CW}$ & -620 & 1.2 & $1: 1.2$ & (S)-Carveol \\
\hline EG AC & Continuous & RVCE & -620 & - & - & (S)-Carveol \\
\hline EG CC & Continuous & RVCE & -620 & 0.35 & $3: 1$ & (S)-Carveol \\
\hline $\mathrm{CO}$ & Continuous & RVCE & -620 & 0.35 & $3: 1$ & N.D. \\
\hline EG AC & Discontonuous & $\mathrm{CW}$ & -620 & - & - & (S)-Carveol \\
\hline EG CC & Discontonuous & $\mathrm{CW}$ & -620 & 0.77 & $1.5: 1$ & $(S)$-Carveol + $(S)$-Carvone $(1: 1)$ \\
\hline $\mathrm{CO}$ & Discontonuous & $\mathrm{CW}$ & -620 & 0.77 & $1.5: 1$ & (S)-Carveol \\
\hline EG AC & Discontonuous & RVCE & -620 & - & - & (S)-Carveol \\
\hline EG CC & Discontonuous & RVCE & -620 & 0.25 & $4: 1$ & (S)-Carveol \\
\hline $\mathrm{CO}$ & Discontonuous & RVCE & -620 & 0.25 & $4: 1$ & N.D. \\
\hline
\end{tabular}

Note: All experiments contained $(R)$-limonene in an initial concentration of $1.0 \mathrm{mmol} \cdot \mathrm{L}^{-1}$ and acetone $30 \%$. N.D.: Not determinated. 